\title{
RANCANG BANGUN APLIKASI BANK DATA BERBASIS WEB DI LINGKUNGAN SKPD KABUPATEN LEBAK
}

\author{
Riyan Naufal Hay's ${ }^{1}$, Ayu Purnamasari ${ }^{2}$, Adam Maulana ${ }^{3}$ \\ ${ }^{1,2.3}$ Program Studi Sistem Informasi Fakultas Teknologi Informasi Universitas Serang Raya \\ Jalan Raya Serang-Cilegon KM. 5 Taman Drangong Serang, Banten \\ ${ }^{1}$ riyan.unsera@gmail.com, \\ 2 ayupurnamasarifaliza@gmail.com, \\ adamnmaulana@gmail.com
}

\begin{abstract}
Abstrak- Aplikasi Bank data yang dibangun di lingkungan SKPD (Satuan Kerja Perangkat Daerah) digunakan untuk menintegrasikan data pemerintah daerah secara terpusat dan tersingkronisasi, juga sebagai manajemen arsip berkas data fisik ke digital pada setiap SKPD, yang dikelola oleh Dinas Komunikasi dan Informatika Kabupaten Lebak (DISKOMINFO), Penelitian ini bertujuan untuk mempermudah setiap SKPD dalam memberikan informasi data pemerintahan yang bersifat publik kepada SKPD lain. Penelitian ini dikembangkan dengan berbasis web menggunakan framework yii dan database MySQL. Penelitian ini dilakukan dengan menggunakan metode observasi, kuisioner dan wawancara. Observasi, kuisioner dan wawancara dilakukan kepada pegawai DISKOMINFO Kabupaten Lebak dengan jabatan Staff IT. Data lalu dianalisis sehingga menghasilkan rancangan sistem dengan menggunakan metode Unifield Modelling Language (UML).Penelitian dilakukan di DISKOMINFO Kabupaten Lebak tanggal 30 Maret 2017 sampai 31 Agustus 2017. Berdasarkan hasil penelitian dapat disimpulkan bahwa penerapan sistem informasi bank data untuk menintegrasikan data secara terpusat dan manajemen arsip data fisik ke digital.
\end{abstract}

Kata kunci : Aplikasi, Arsip, Bank data, Web

\section{PENDAHULUAN}

Komputer menawarkan segala kemudahan dalam membantu aktivitas manusia sebagai personal maupun kelompok dalam menjalankan tugasnya. Dari aktifitas tersebut menghasilkan berbagai informasi penting yang tersimpan dalam bentuk dokumen dengan ekstensi tertentu sesuai perangkat lunak yang digunakan. Teknologi informasi dapat mempermudah komunikasi dan mempercepat seseorang mendapatkan informasi yang dibutuhkan melalui sebuah media publikasi informasi dan tersimpan secara komputerisasi.

Dinas Komunikasi dan Informatika (DISKOMINFO) Kabupaten Lebak adalah salah satu Satuan Kerja Perangkat Daerah (SKPD) yang dibentuk untuk melaksanakan tugas pokok penyusunan dan pelaksanaan kebijakan urusan pemerintahan daerah di bidang Komunikasi dan Informatika. Bertanggung jawab atas pusat pengolahan informasi dalam lingkungan Pemerintahan daerah Kabupaten Lebak.

Saat ini DISKOMINFO Kabupaten Lebak melakukan penyimpanan data laporan yang bersifat offline atau bersifat fisik, hasil laporan dari SKPD yang masih manual dan disimpan dalam sebuah file didalam ruangan. Hal ini menyebabkan kapasitas ruangan semaikin penuh setiap tahunnya dan proses pencarian menjadi kurang efektif serta membutuhkan waktu lama bagi yang ingin mengetahui tentang data informasi dari setiap SKPD di daerah Kabupaten Lebak. Namun belum tersedianya layanan yang menyediakan pusat penyimpanan data tersebut.

Bank data bagi instansi sangat penting karena data yang di dapatkan diubah menjadi informasi yang berguna bagi setiap SKPD, dengan sebuah tempat penyimpanan yang terkomputerisasi maka Bank data selalu memperbaharui data-data yang ada agar tidak tertinggal oleh perkembangan zaman.

Untuk mengatasi hal ini Bank data yang memuat informasi mengenai laporan dari setiap SKPD daerah Kabupaten Lebak akan dimuat dalam sebuah rancangan web sehingga perangkat kerja di lingkungan Kabupaten Lebak dapat dengan mudah mengaksesnya dimanapun dan kapanpun tanpa harus mendatangi DISKOMINFO Kabupaten Lebak, selain itu bagi instansi yang mengelola Bank data tidak perlu lagi menyimpan data informasi data berupa fisik dalam sebuah ruangan, hal ini tentunya akan lebih efektif serta menghemat waktu sehingga data informasi yang di dapatkan DISKOMINFO Kabupaten Lebak akan lebih cepat.

Lebak, layanan Bank data dirasa cukup tepat sebagai alternatif SKPD untuk mendapatkan informasi secara terpusat. Oleh karena itu pada penelitian kali ini penulis akan membuat sebuah sistem aplikasi bank data berbasis website 
dengan memilih judul skripsi yaitu " Rancang Bangun Aplikasi Bank Data Berbasis Web Di Lingkungan SKPD Kabupaten Lebak".

\section{METODOLOGI PENELITIAN}

\section{A. Model Waterfall}

Metode yang digunakan untuk membangun sistem ini adalah Model Waterfall. Model ini merupakan sebuah pendekatan terhadap pengembangan perangkat lunak yang sistematik, dengan beberapa tahapan, yaitu: System Engineering, Analysis, Design, Coding, Testing dan Maintenance.

Untuk lebih jelasnya tahapan-tahapan dari Paradigma Waterfall dapat dilihat pada gambar berikut:

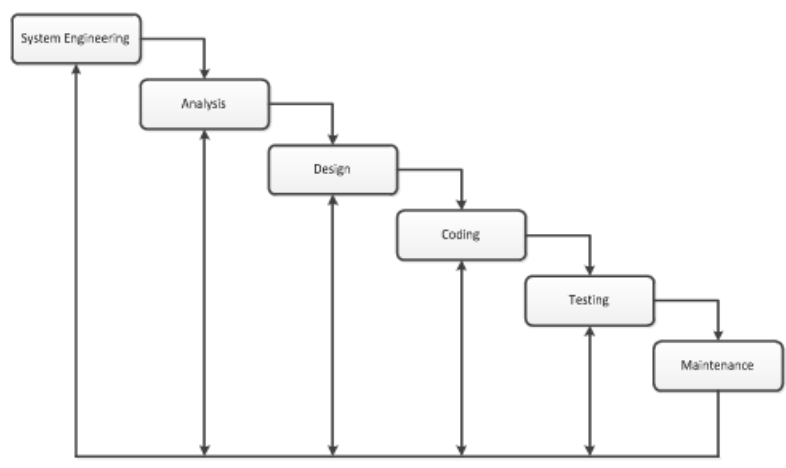

Gambar 1. Paradigma Waterfall (Classic Life Cycle)

Penjelasan Model Waterfall:

1. System Engineering, merupakan bagian awal dari pengerjaan suatu proyek perangkat lunak. Dimulai dengan mempersiapkan segala hal yang diperlukan dalam pelaksanaan proyek.

2. Analysis, merupakan tahapan dimana System Engineering menganalisis segala hal yang ada pada pembuatan proyek atau pengembangan perangkat lunak yang bertujuan untuk memahami sistem yang ada, mengidentifikasi masalah dan mencari solusinya.

3. Design, tahapan ini merupakan tahap penerjemah dari keperluan atau data yang telah dianalisis ke dalam bentuk yang mudah dimengerti oleh pemakai (user),tools yang digunakan untuk tahap ini yaitu UML.

4. Coding, yaitu menerjemahkan data yang dirancang ke dalam bahasa pemrograman yang telah ditentukan.
5. Testing, merupakan uji coba terhadap sistem atau program setelah selesai dibuat, metode yang digunakan yaitu blackbox.

6. Maintenance, yaitu penerapan sistem secara keseluruhan disertai pemeliharaan jika terjadi perubahan struktur, baik dari segi software maupun hardware.

\section{PERANCANGAN}

A. Analisa Sistem

Analisis sistem dalam suatu lembaga pemerintahan sangat penting karena fungsi dari analisis itu sendiri yaitu untuk mengetahui bagaimana sistem itu berjalan agar sistem yang di buat dapat menghasilkan output yang dinginkan dan dapat mencapai tujuan yang di rencanakan.

Prosedur adalah kumpulan dari proses dalam suatu sistem yang saling terkait antara satu dengan yang lainnya untuk mencapai tujuan yang telah diterapkan. Adapun prosedur dan flowchart sistem yang berjalan proses keluar/masuk dokumen di DISKOMINFO Kabupaten Lebak.

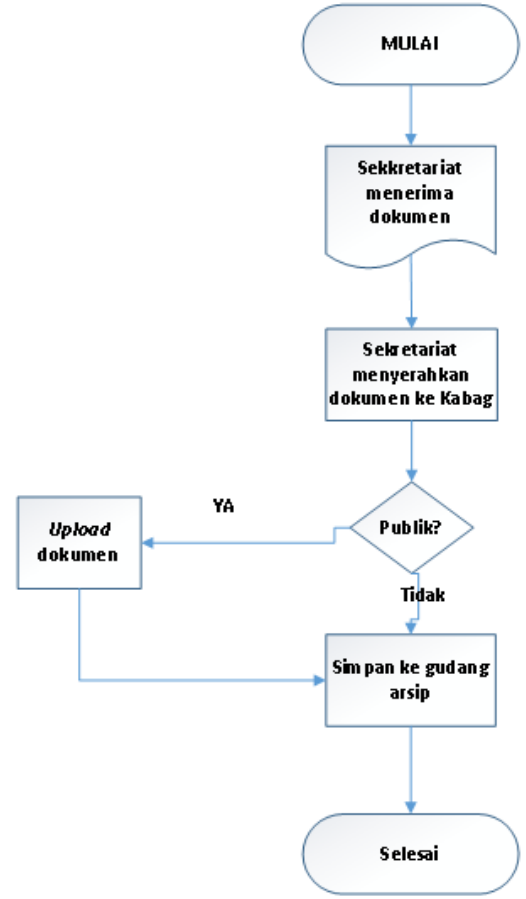

Gambar 2. Flowchart Keluar/Masuk Dokumen DISKOMINFO Kabupaten Lebak

\section{B. Usecase Diagram}

Use case diagram menjelaskan manfaat dari aplikasi jika dilihat dari sudut pandang orang yang berada diluar sistem. Diagram ini menunjukan fungsionalitas suatu sistem atau kelas dan bagaimana sistem berinteraksi dengan dunia luar.

Use case bekerja dengan cara mendeskripsikan tipikal antara pengguna sebuah sistem dengan sistemnya sendiri melalui sebuah cerita bagaimana sebuah sistem di buat. 
Aplikasi Bank data ini use case yang terlibat, antara lain sebagai berikut:

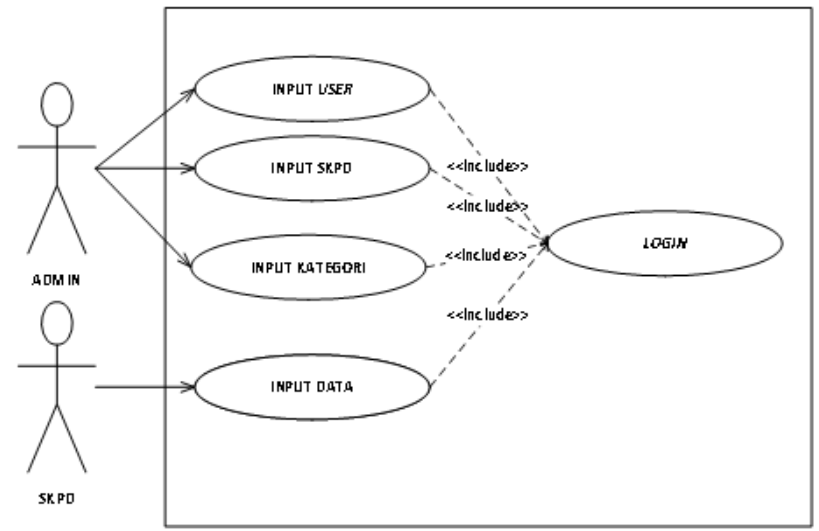

Gambar 3. Use Case Diagram Aplikasi Bank Data

\section{ERD Aplikasi Bank Data}

Entity Relationship Diagram (ERD) adalah hubungan atau relasi antar entitas. ERD berfokus pada data dengan menunjukkan jaringan data yang ada untuk suatu sistem yang diberikan. ERD sangat berguna bagi aplikasi dimana data dan hubungan yang mengatur data sangatlah kompleks.

Entitas yang terlibat dalam bank data ini adalah user, skpd, data dan kategori. ERD aplikasi bank data adalah sebagai berikut:

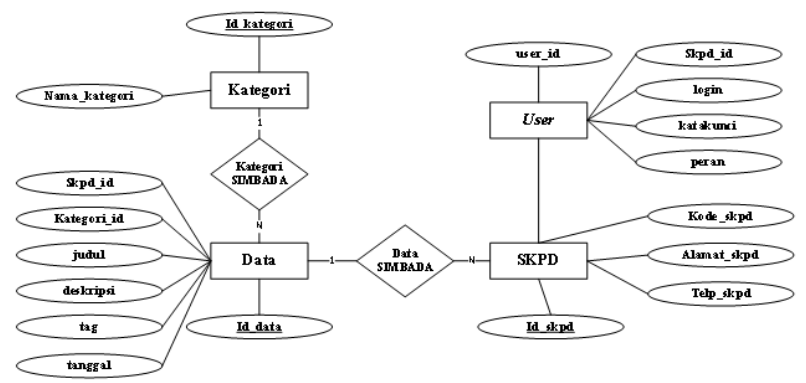

Gambar 4. ERD Aplikasi Bank Data

\section{HASIL DAN PEMBAHASAN}

A. Halaman Login

Sebelum masuk ke halaman menu, user diharuskan melakukan login terlebih dahulu agar bisa mengakses menu yang ada pada aplikasi bank data dengan memasukkan username dan password yang terdaftar didalam basisdata sistem informasi bank data.

Pengguna meng-input data sesuai level user yang digunakan, yaitu Admin dan SKPD. Jika data user yang dimasukan valid maka akan muncul halaman login ditampilkan sebagai berikut.

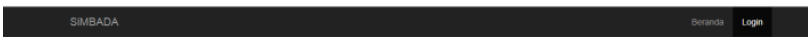

Gambar 5. Halaman Login

B. Tampilan Menu User

Pada menu ini menampilkan tabel data user yang di dalamnya sudah terdapat menu untuk memanipulasi data yang terdiri dari lihat, ubah dan hapus.
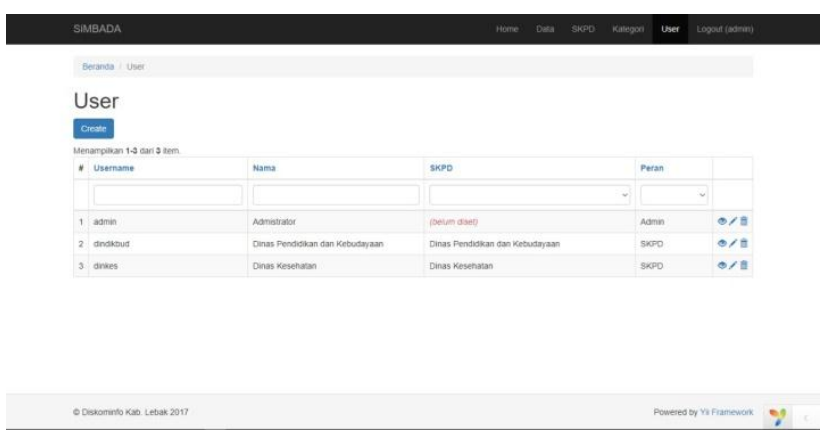

Gambar 6. Halaman Menu User

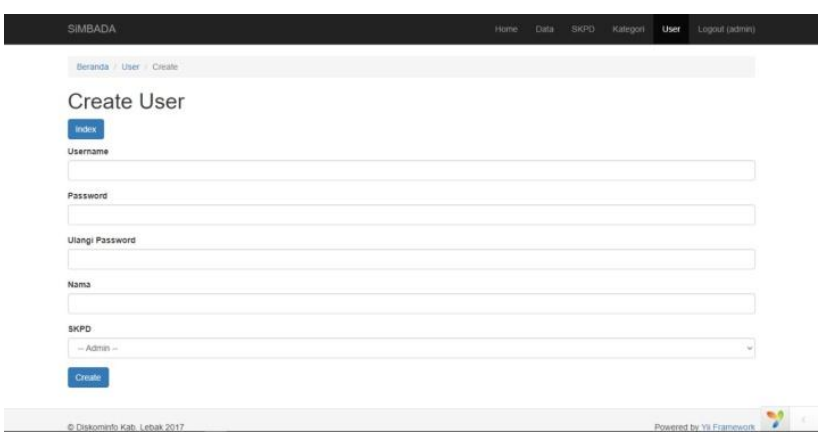

Gambar 7. Halaman Form User

C. Tampilan Menu SKPD

Pada menu ini menampilkan tabel data SKPD yang di dalamnya sudah terdapat menu untuk memanipulasi data yang terdiri dari lihat, ubah dan hapus.

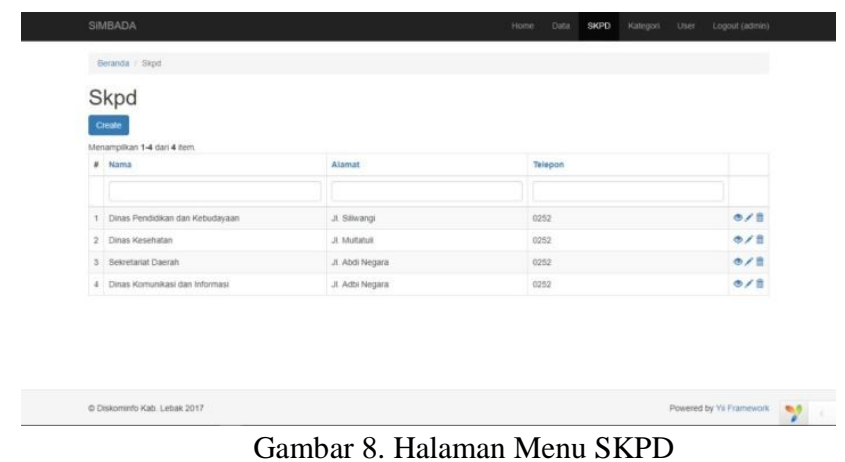

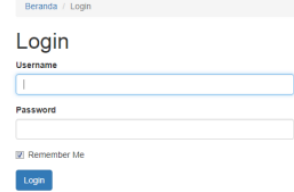


D. Tampilan Menu Data

Pada menu ini menampilkan tabel data yang di dalamnya sudah terdapat menu untuk memanipulasi data yang terdiri dari lihat, ubah dan hapus.

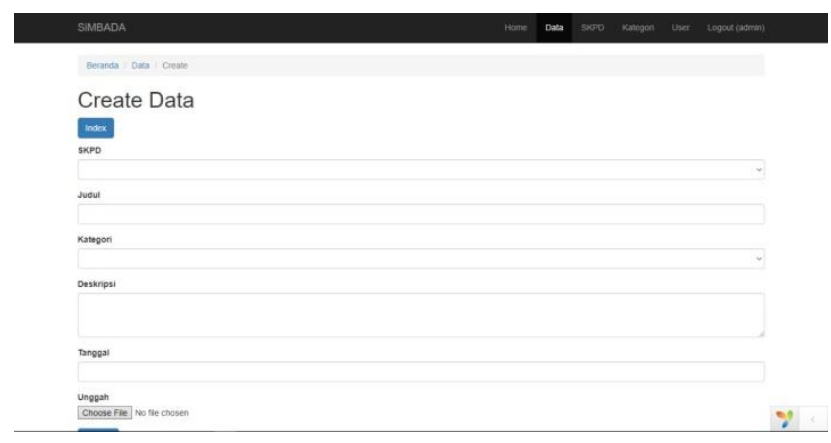

Gambar 9. Halaman Form Data

E. Tampilan Menu Kategori

Pada menu ini menampilkan tabel kategori yang di dalamnya sudah terdapat menu untuk memanipulasi data yang terdiri dari lihat, ubah dan hapus.

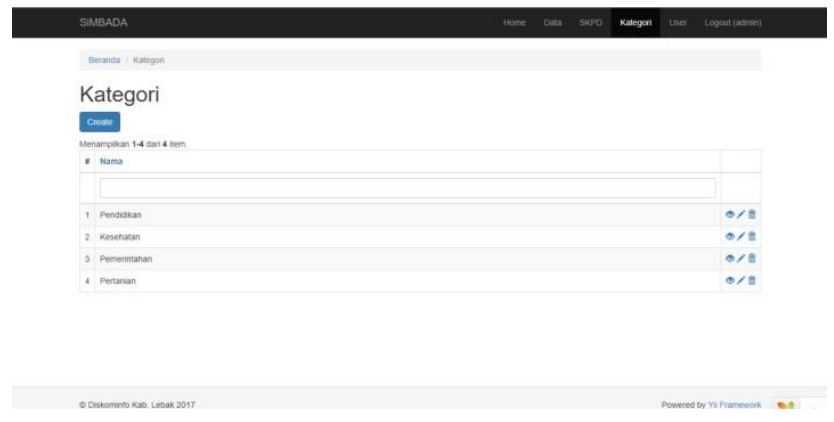

Gambar 10. Halaman Menu Kategori

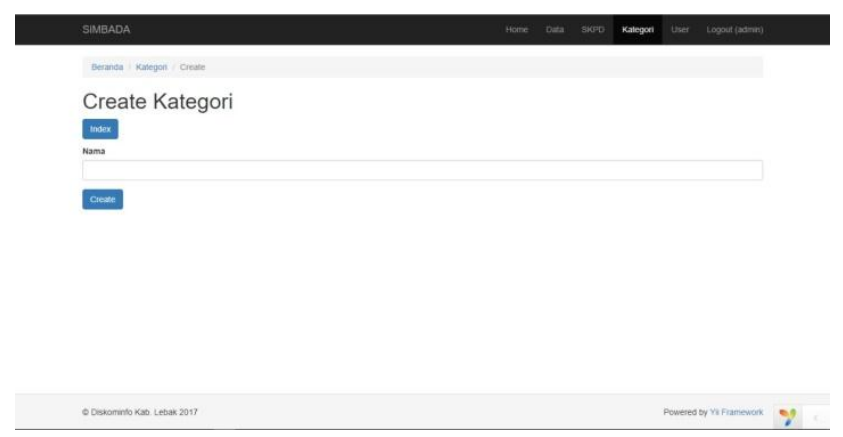

Gambar 11. Halaman Form Kategori

\section{KESIMPULAN}

A. Kesimpulan

Aplikasi bank data ini dirancang dan dibuat sebagai solusi untuk menyimpan dan mengatur dokumen SKPD yang terdaftar di DISKOMINFO Kabupaten Lebak, sehingga setiap SKPD dapat dengan mudah mengakses selama 24 jam tanpa harus mendatangi kantor DISKOMINFO Kabupaten Lebak

DISKOMINFO Kabupaten Lebak masih menyimpan dokumen pengarsipan kedalam box file kemudian ditempatkan ke tempat penyimpanan (gudang) arsip yang setiap tahunnya akan semakin menumpuk sehingga jika ada karyawan yang membutuhkan data informasi akan membutuhkan waktu yang lama, untuk itu Aplikasi bank data menjadi solusi atas permasalahan penyimpanan data berkas di DISKOMINFO Kabupaten Lebak.

Aplikasi bank data diterapkan berbasis web di DISKOMINFO Kabupaten Lebak dibuat bersifat intern, artinya pengguna program ini hanya level tertentu yang memiliki hak akses terhadap sistem ini yaitu admin dan SKPD.

B. Saran

Sebaiknya seluruh SKPD yang ada di Lingkungan Kabupaten Lebak bisa terdaftar menjadi user sehingga semua data pemerintahan bisa terintegrasi secara langsung pada pusatnya.

Diharapkan adanya pembatasan jumlah user berlevel SKPD. Perlu pengembangan lebih lanjut agar jumlah pengguna dapat ditekan untuk meminimalisir penyalahgunaan akun berlevel SKPD.

\section{REFERENSI}

[1]. Amin Sukron, Siahaan Kondar. (2016). "Analisis dan Perancangan Sistem Informasi Manajemen Arsip Berbasis Web Pada Sekolah Tinggi Ilmu Tarbiyah (STIT) Kabupaten Tebo". Jurnal Manajemen Sstem Informasi Vol. 1, No. 1.

[2]. Christianti,Meliana. (2008). Konsep Praktis Sistem Pengarsipan dan Akses. Bandung: Informatika.

[3]. Irwanto, Djon. (2005). Perancangan Object Oriented Software dengan UML. Jakarta: Andi Publishing.

[4]. Latif Fauziah, Pratama Aditya Wirangga. (2015). "Perancangan Sistem Informasi Manajemen Arsip Elektronik (E-Arsip) Berbasis Microsoft Acces Pada PT. HITEST'.Batam: Politeknik Negeri Batam.

[5]. Nuraisah. (2014). "Perencanaan Pengembangan Sistem Informasi Pembayaran Uang Kuliah Dengan Metode SDLC Waterfall". Jurnal Teknologi dan Rekayasa Vol. 19, No. 3.

[6]. Pascapraharastyan, R. A, Supriyanto,Antok dan Sudarmaningtyas,Pantjawati. (2014). "Rancang Bangun Sistem Informasi Manajemen Arsip Rumah Sakit Bedah Surabaya Berbasis Web". Jurnal Sistem Informasi(JSIKA) Vol. 3, No. 1.

[7]. Puspita Sari, M. (2014). "Sistem Informasi Bank Data dan Penelusuran Tugas Akhir dan Skripsi Berbasis Web (Studi Kasus STMIK PRINGSEWU)".Lampung: STMIK PRINGSEWU.

[8]. Sawitri Isma, Sinaga Tantri Hidyati. (2014). "Sistem Informasi Manajemen Arsip Penelitian".Medan: STT Harapan Medan. 
[9]. Sugiyono. (2014). Metode Penelitian Kuantitatif Kualitatif dan R\&D. Bandung: Alfabeta.

[10]. Sucipto. (2011). Konsep dan Teknik Pengembangan Sistem Berbasis Teknologi Informasi. Banten: Dinas Pendidikan Provinsi Banten.

[11]. Sharive. (2014). Proyek Membangun Website dengan Yii Framework. Jakarta: Lokomedia. 